\title{
Primary systemic therapy for patients with brain metastases from lung cancer ineligible for targeted agents
}

\author{
Carsten Nieder ${ }^{1,2}\left(\mathbb{D} \cdot \operatorname{Siv}\right.$ G. Aanes ${ }^{1} \cdot$ Ellinor Haukland $^{1,2,3}$
}

Received: 7 November 2021 / Accepted: 4 January 2022 / Published online: 12 January 2022

(c) The Author(s) 2022

\begin{abstract}
Purpose The purpose of this study was to evaluate overall survival after systemic therapy, largely chemotherapy, in patients with small cell or non-small cell lung cancer and brain metastases. After completion of systemic therapy, some patients received planned brain irradiation, while others were followed.

Methods Retrospective cohort study.

Results Thirty-eight patients were included (28 small cell, 20 followed with imaging). Six of these 20 patients (30\%) received delayed radiotherapy during follow-up. Planned radiotherapy ( $n=18$, intention-to-treat) was associated with longer survival from diagnosis of brain metastases, median 10.8 versus 6.1 months, $p=0.025$. Delayed radiotherapy still resulted in numerically better survival than no radiotherapy at all (median 8.8 versus 5.3 months, not significant). If calculated from the start of delayed radiotherapy, median survival was only 2.7 months. In a multivariable analysis, both Karnofsky performance status $\geq 70(p=0.03)$ and planned radiotherapy $(p=0.05)$ were associated with better survival.

Conclusion In patients ineligible for targeted agents, planned radiotherapy in a modern treatment setting was associated with longer survival compared to no radiotherapy. Timing and type of radiotherapy in such patients should be evaluated in prospective trials to identify patients who might not need planned radiotherapy.
\end{abstract}

Keywords Lung cancer $\cdot$ Brain metastases $\cdot$ Chemotherapy $\cdot$ Systemic therapy $\cdot$ Survival $\cdot$ Pattern of care

\section{Introduction}

With increasing primary tumor $(\mathrm{T})$ and lymph-node $(\mathrm{N})$ stage, both small cell lung cancer (SCLC) and non-small cell lung cancer (NSCLC) tend to metastasize to the brain (Sacks and Rahman 2020). Certain molecular features of NSCLC, e.g., epidermal growth factor receptor (EGFR) mutations, modulate the risk of brain metastases, while also representing targets for primary systemic therapy (Andratschke et al.

Carsten Nieder

carsten.nieder@nlsh.no

1 Department of Oncology and Palliative Medicine, Nordland Hospital, 8092 Bod $\varnothing$, Norway

2 Department of Clinical Medicine, Faculty of Health Sciences, UiT-The Arctic University of Norway, 9037 Troms $\emptyset$, Norway

3 SHARE-Center for Resilience in Healthcare, Faculty of Health Sciences, Department of Quality and Health Technology, University of Stavanger, 4036 Stavanger, Norway
2019; Wang et al. 2021). A complex decision-making is required when recommending primary systemic therapy. For example, the simultaneous presence of widespread extracranial disease, an actionable mutation and limited, asymptomatic brain disease may prompt the multidisciplinary tumor board (MDT) to recommend this strategy. Despite a longstanding, historical interest in primary cytotoxic chemotherapy for selected patients with SCLC and NSCLC with brain metastases (Minotti et al. 1998; Bernardo et al. 2002; Chen et al. 2008; Lee et al. 2008), early administration of radiotherapy was common (Nieder et al. 2019a, b; Kepka et al. 2021; Du et al. 2021). Under special circumstances, surgical resection of a single brain metastasis may be a viable option (Fuchs et al. 2021).

Also at the authors' institution, which has an extremely low rate of patients with EGFR mutations or other targetable alterations influencing first-line treatment (Nieder et al. 2020), early radiotherapy was the prevailing strategy for patients with brain metastases from lung cancer undergoing active treatment rather than supportive, palliative measures. Nevertheless, on a case-by-case basis, the MDT sometimes 
recommended primary cytotoxic chemotherapy and recently immune checkpoint inhibitors (ICI) or ICI plus chemotherapy if no actionable target was present. The purpose of the present study was to evaluate the survival and several secondary outcomes in these consecutively treated patients with SCLC or NSCLC.

\section{Patients and methods}

A retrospective single-institution quality-of-care analysis was performed, based on electronic health records and a previously utilized brain metastases database, which does not include patients with leptomeningeal spread (Nieder et al. 2019b, 2020). Magnetic resonance imaging was used to diagnose the brain metastases, without histological confirmation. After exclusion of patients managed with best supportive care or upfront local treatment (surgery, any type of radiotherapy), those who received primary drug-based treatment for SCLC or NSCLC without actionable mutations in the time period 2007-2020 were included. Consolidation radiotherapy after the last cycle of chemotherapy was permitted. However, sandwich radiotherapy between the initial cycles of chemotherapy (upfront combined treatment) was not permitted. None of the patients had received prophylactic cranial irradiation (PCI). Both synchronous and metachronous brain metastases were permitted. The MDT selected the type of systemic therapy according to national Norwegian guidelines provided by the Norwegian Lung Cancer Group. If indicated, maintenance treatment was administered. Later during the course of the disease, further lines of systemic therapy and delayed (salvage) braindirected treatments could be administered, as judged appropriate by the MDT. For example, one patient who started with chemotherapy, later received three sequential courses of stereotactic radiosurgery before proceeding to whole-brain irradiation. None of the patients received targeted agents in any line of treatment. Bevacizumab was not utilized.

Actuarial survival from the day of treatment initiation was calculated with the Kaplan-Meier method and compared between subgroups with the log-rank test. Thirty-two patients had died and six patients were censored at the time of their last follow-up (median 18 months). Associations between different variables of interest were assessed with the Chi-square or Fisher's exact probability test (two-tailed). The validated prognostic score LabBM (serum hemoglobin, platelets, albumin, C-reactive protein, and lactate dehydrogenase) was calculated as previously described (Berghoff et al. 2017; Nieder et al. 2019c). The impact of continuous variables such as age and number of brain metastases on survival was examined in univariate Cox analyses. A multivariate forward conditional Cox analysis of prognostic factors for survival was then performed. A $p$ value $<0.05$ was considered statistically significant. Due to limited patient numbers, a $p$ value $<0.15$ was selected in the initial analyses, e.g., when deciding which parameters to include in the multivariate Cox model. Intra- and extracranial response rates and patterns of progression were not evaluated. The database created for the purpose of this quality-of-care analysis does not require approval by the local Ethics Committee (REK Nord).

\section{Results}

Among 38 patients included in the study, 28 had SCLC (74\%), seven adenocarcinoma (18\%), two neuroendocrine NSCLC, and one squamous cell carcinoma. Except for two patients, all had their brain metastases diagnosed when the initial diagnosis of lung cancer was made (synchronous brain metastases). In ten patients (26\%), clinical symptoms of brain metastases were present. The others had stagingdetected, asymptomatic lesions. Further baseline data are shown in Table 1. Systemic therapy consisted of platinumbased doublets in 32 patients (84\%), typically four cycles. Six patients with NSCLC received ICI monotherapy $(n=2)$ or ICI with platinum doublet chemotherapy $(n=4)$. As indicated in Fig. 1, 18 patients (47\%) were scheduled for planned radiotherapy after their first line of systemic treatment, while

Table 1 Patient characteristics ( $n=38$, time period 2007-2020)

\begin{tabular}{lll}
\hline Parameter & $n$ & $\%$ \\
\hline Female sex & 20 & 53 \\
Male sex & 18 & 47 \\
No extracranial metastases & 10 & 26 \\
Liver metastases & 9 & 24 \\
Bone metastases & 12 & 32 \\
Only one extracranial distant site affected & 7 & 18 \\
Two such organs affected, e.g., bone +liver & 13 & 34 \\
Three or more organs affected & 8 & 21 \\
No brain radiotherapy at all & 15 & 39 \\
Karnofsky performance status 90-100 & 7 & 18 \\
Karnofsky performance status 70-80 & 27 & 71 \\
Karnofsky performance status $<70$ & 4 & 11 \\
Whole-brain radiotherapy* & 19 & 50 \\
Higher dose radiotherapy & 4 & 11 \\
Single brain metastasis & 10 & 26 \\
Median number of brain metastases, range & 3 & $1-50$ \\
Median size of the largest lesion, range (mm) & 10 & $3-30$ \\
Median age, range (years) & 68.5 & $46-82$ \\
Median LabBM score, range (points) & 1.5 & $0-3$ \\
\hline
\end{tabular}

* 18 patients had received $30 \mathrm{~Gy}$ in 10 fractions of $3 \mathrm{~Gy}$ and one $25 \mathrm{~Gy}$ in 10 fractions of 2.5 Gy (higher dose means stereotactic radiotherapy without whole-brain radiotherapy $(n=2)$ or simultaneous integrated boost whole-brain radiotherapy $(n=2)$ ) 
Fig. 1 Study diagram

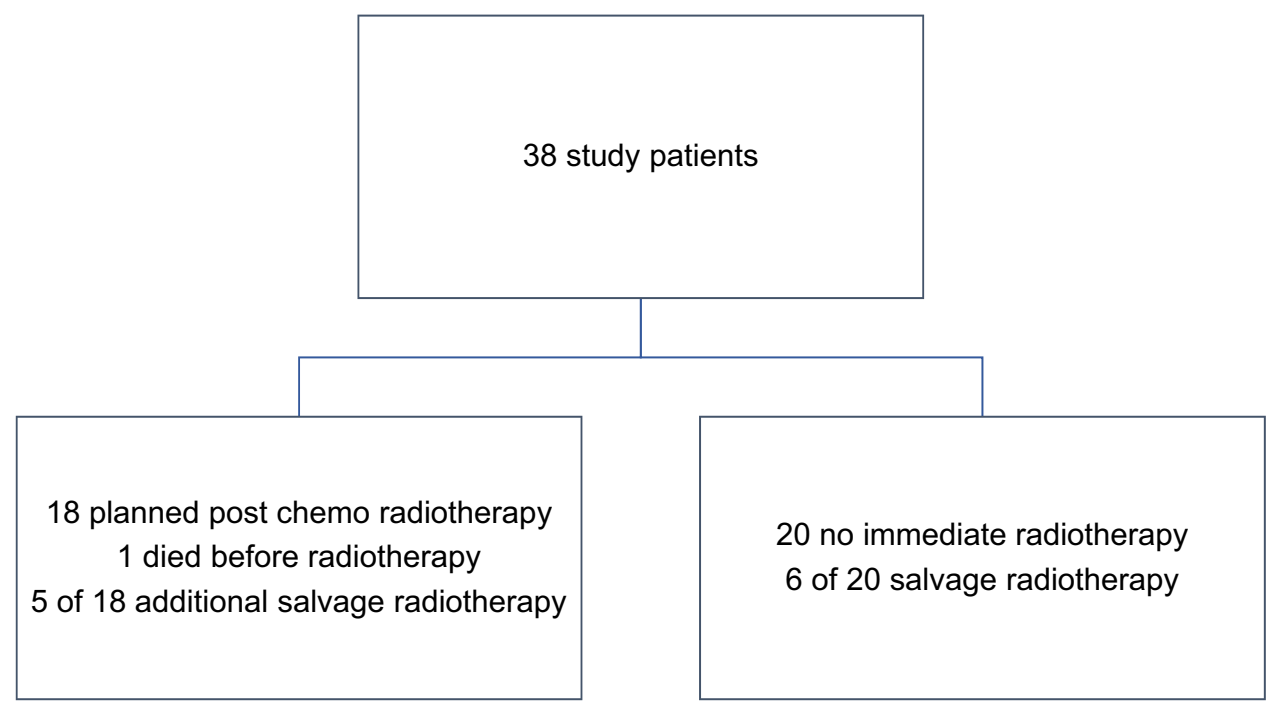

20 patients $(53 \%)$ were followed with brain imaging. Age, Karnofsky performance status (KPS), presence of symptoms, and number of lesions were not significantly different between the two groups. However, significantly more patients without extracranial metastases were scheduled for planned radiotherapy ( 80 versus $36 \%, p=0.03$ ). Six of 20 patients $(30 \%)$ followed with imaging surveillance received delayed or salvage radiotherapy during the course of the disease. Among patients with planned radiotherapy, 5 (28\%) received at least one more course of brain irradiation due to progression or development of new lesions (Table 2).

For all patients, median overall survival was 8.8 months (95\% confidence interval (CI) 7.9-9.7 months). For all irradiated patients regardless of timing, median overall survival from the start of radiotherapy was 7.1 months $(95 \%$ CI 4.2-10.0 months). Planned radiotherapy ( $n=18$ on an intention-to-treat basis) was associated with longer survival from diagnosis of brain metastases, median 10.8 versus 6.1 months, $p=0.025$ (Fig. 2). Delayed salvage radiotherapy still resulted in numerically better survival than no radiotherapy at all (median 8.8 versus 5.3 months, not significant). If calculated from the start of delayed salvage radiotherapy, median survival was only 2.7 months.

Regarding survival after diagnosis of brain metastases, all baseline parameters summarized in the Results section including Table 1 were tested for their prognostic impact. Several prognostic factors known from previous studies of radiotherapy were not associated with this endpoint (age, number, and size of brain metastases, LabBM score; all $p>0.15)$. The same was true for the diagnostic setting (symptoms yes/no; $p=0.22$ ) and histologic type of lung cancer $(p=0.3)$. In contrast, the absence of extracranial metastases was potentially important (median survival 10.5 versus 8.3 months, $p=0.06$ ). Reduced survival was observed in the presence of liver metastases (5.2 versus 9.7 months, $p=0.05)$ and bone metastases (6.1 versus 9.0 months, $p=0.08$ ). KPS $<70$ was highly significant (median 4.2 versus 8.9 months, $p=0.005)$. These four parameters and the radiotherapy setting (planned versus imaging followup/surveillance) were included in the multivariable Cox model. Both KPS $\geq 70(p=0.03)$ and planned radiotherapy $(p=0.05)$ were more important than absence of extracranial metastases $(p=0.18)$, no liver metastases $(p=0.28)$, and no bone metastases $(p=0.45)$.

Among 32 patients who had died, the cause of death was unknown in three, intracranial progression in five, extracranial progression in 17 , and difficult to judge in seven who had active brain metastases, but also extracranial progression at their last hospital visit and who died at home or in a nursing home.

\section{Discussion}

As shown in older studies (Minotti et al. 1998; Bernardo et al. 2002; Chen et al. 2008; Lee et al. 2008), the fact that brain metastases with permeable blood-brain barrier may respond to systemic chemotherapy has stimulated researchers to pursue strategies of delayed or completely eliminated brain irradiation, particularly after the advent of targeted agents for molecularly defined types of NSCLC and in the era of effective ICI therapy. Most patients harbor both, brain and extracranial distant metastases (Nieder et al. 2021a), are not in an oligometastatic setting and require systemic treatment to optimize survival outcomes (Nieder et al. 2021b). It is not always easy to select the patients who are likely to derive added value from brain irradiation, a treatment which also can add toxicity. The present study evaluated patients with brain metastases from lung cancer not eligible for targeted drugs such as EGFR tyrosine kinase inhibitors, 
Table 2 Detailed description of re-irradiated patients $(n=5)$

\begin{tabular}{|c|c|c|c|c|c|}
\hline Sex, age (years) & Tumor characteristics & Treatment & First radiotherapy & Second radiotherapy & Survival* \\
\hline Male, 67 & $\begin{array}{l}\text { SCLC, asymptomatic single } \\
\text { BM, skin and soft tissue } \\
\text { metastases (Dec. 2015) }\end{array}$ & Planned WBRT & $\begin{array}{l}\text { WBRT } 10 \text { fractions of } 3 \text { Gy } \\
\text { (Mar. 2016) }\end{array}$ & SRS (Jan. 2017) & 19.0 \\
\hline Female, 69 & $\begin{array}{l}\text { SCLC, } 8 \text { asymptomatic BM, } \\
\text { bone and pleural metastases } \\
\text { (Jun. 2018) }\end{array}$ & Planned WBRT & $\begin{array}{l}\text { WBRT } 10 \text { fractions of } 3 \text { Gy } \\
\text { (Sep. 2018) }\end{array}$ & $\begin{array}{l}\text { WBRT } 10 \text { fractions of } 2.5 \text { Gy } \\
\text { (plus } 0.5 \text { Gy SIB; Oct. } 2019 \text { ) }\end{array}$ & 19.0 \\
\hline Female, 69 & $\begin{array}{l}\text { SCLC, } 3 \text { asymptomatic BM, } \\
\text { adrenal gland metastases } \\
\text { (Aug. 2019) }\end{array}$ & Planned WBRT & $\begin{array}{l}\text { WBRT } 10 \text { fractions of } 3 \text { Gy } \\
\text { (plus 0.5 Gy SIB; Dec. 2019) }\end{array}$ & $\begin{array}{l}\text { SFRT } 6 \text { fractions of } 5 \text { Gy } \\
\text { (Aug. 2020) }\end{array}$ & 19.2 \\
\hline Female, 76 & $\begin{array}{l}\text { Squamous cell cancer, } 3 \\
\text { asymptomatic BM, no } \\
\text { extracranial met. (May 2019) }\end{array}$ & Planned SRS & SRS (Sep. 2019) & $\begin{array}{l}\text { SRS (Dec. } 2019 \text { and Feb. } \\
\text { 2020), WBRT } 10 \text { fractions of } \\
3 \text { Gy (Aug. 2020) }\end{array}$ & $25.2+$ \\
\hline Female, 61 & $\begin{array}{l}\text { SCLC, } 8 \text { asymptomatic BM, } \\
\text { adrenal gland and lung met. } \\
\text { (Aug. 2019) }\end{array}$ & Planned WBRT & $\begin{array}{l}\text { WBRT } 10 \text { fractions of } 3 \text { Gy } \\
\text { (Dec. 2019) }\end{array}$ & $\begin{array}{l}\text { SFRT } 7 \text { fractions of } 4.5 \text { Gy } \\
\text { (Jul. 2020) }\end{array}$ & 15.4 \\
\hline
\end{tabular}

$S C L C$ small cell lung cancer, $B M$ brain metastases, $C T x$ platinum-based chemotherapy, WBRT whole-brain radiotherapy, SIB simultaneous integrated boost, $S R S$ stereotactic radiosurgery, $S F R T$ stereotactic fractionated radiotherapy

*Months from diagnosis of brain metastases (+ ongoing)

who initially received systemic therapy, the approach recommended by the institutional MDT for selected patients. Because this strategy still causes debate, our group was interested in the patterns of care and outcomes.

The retrospective study included patients mainly with SCLC, synchronous brain metastases, often but not always asymptomatic lesions, and highly variable extent of brain involvement. In other words, a relatively heterogeneous population was examined, also with regard to treatment. Typically, platinum-based doublets were prescribed and, in case of radiotherapy, whole-brain irradiation (WBRT). Significantly, more patients without extracranial metastases were scheduled for planned radiotherapy ( 80 versus $36 \%, p=0.03$ ), a strategy pursued in almost half of the cohort. Six of 20 patients (30\%) followed with imaging surveillance received delayed or salvage radiotherapy during the course of the disease. This finding supports those of the older studies, which already had suggested that not all patients require brain irradiation. Among patients with planned radiotherapy, 5 (28\%) received at least one more course of brain irradiation due to progression or development of new lesions. In other words, planned radiotherapy does not completely eliminate the threat of brain progression and need for additional treatment. Ideally, clinicians would be able to perform better patient selection at diagnosis, resulting in less need for sequential salvage radiotherapy. On the other hand, in the era of reduced WBRT utilization, sequential administration of several courses of focal radiotherapy has become increasingly accepted (Nieder et al. 2018a).

We found that patients scheduled for planned radiotherapy after completion of systemic treatment had the longest survival. Delayed salvage radiotherapy resulted in a median survival of only 2.7 months. Selection bias often explains why a certain treatment strategy results in superior outcome in non-randomized studies like the present one. The main imbalance between the groups with and without planned radiotherapy was the presence or absence of extracranial metastases. However, after accounting for this and other baseline parameters, the multivariable regression analysis still suggested that planned radiotherapy may improve survival. A definitive recommendation would require additional evidence and data on important aspects of survivorship such as quality of life, cognitive, and neurologic outcomes. The latter require prospective data collection. In the present study, patient-reported outcomes were not available. Given that extracranial progression was a common cause of death, further improvement of extracranial disease control and systemic treatment is needed. In this context, the progress made for NSCLC was more remarkable than for SCLC, the predominant type of cancer in our study. In SCLC, PCI has been shown to improve survival (Kepka et al. 2021). One might argue that the common setting of four cycles of chemotherapy followed by planned WBRT in many SCLC patients in our study resembles the PCI concept. Overall, the median survival in this study (8.8 months) was limited, and so was long-term survival. Previously, we reported a median survival of 5.4 months in patients who received radiotherapy for brain metastases from lung cancer (Nieder et al. 2017).

It is difficult to compare the present study to the literature, because of differences in design and patient characteristics, e.g., predominance of NSCLC. Barlesi et al. treated NSCLC patients with brain metastases ineligible for (radio) surgery with up to six cycles of cisplatin and pemetrexed 
Fig. 2 Actuarial overall survival (Kaplan-Meier plot) stratified for planned radiotherapy (intention-to-treat, $n=18$ ), $p=0.025$ (log-rank test)

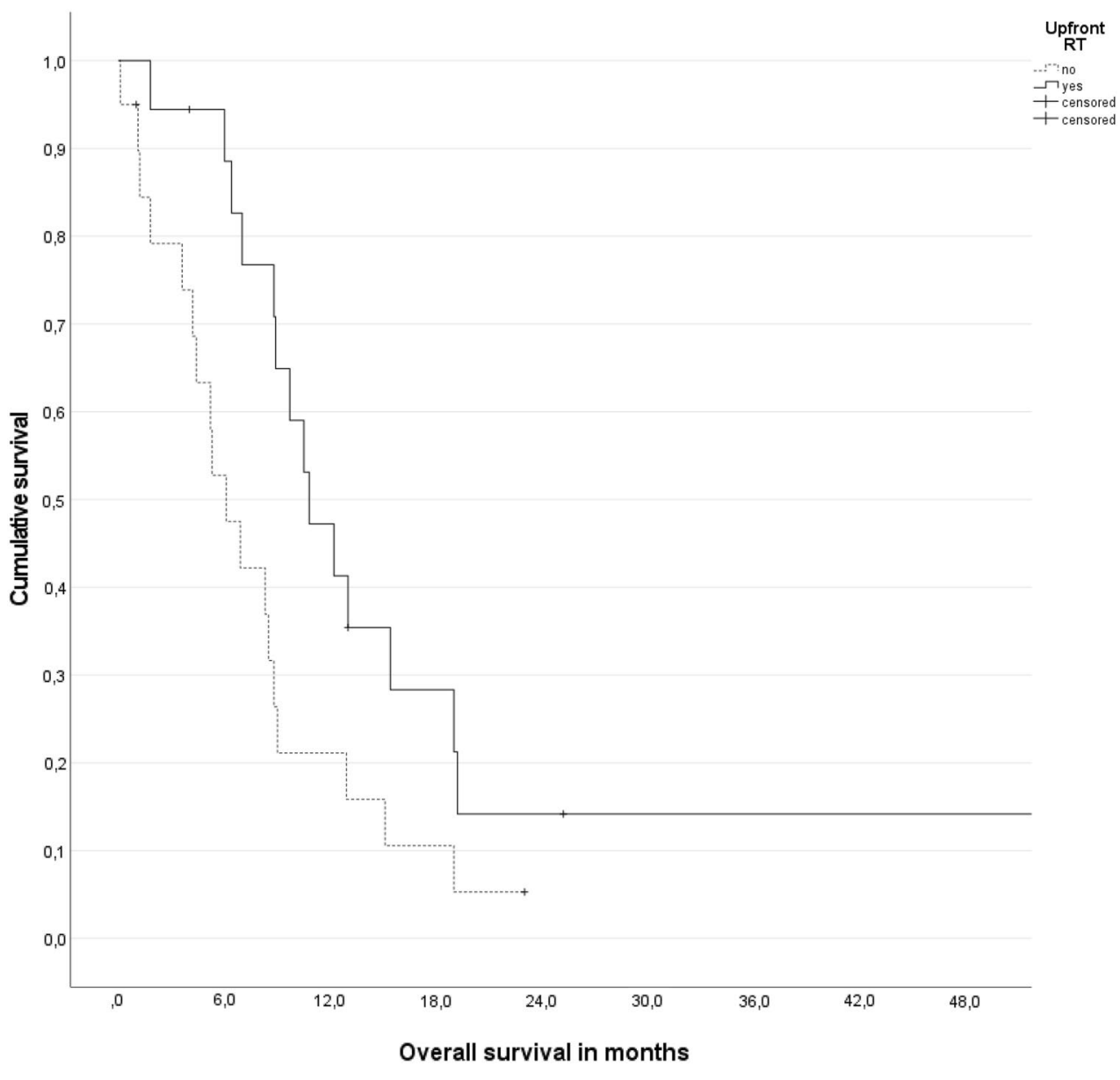

every 3 weeks (Barlesi et al. 2011). WBRT was given in case of disease progression or at chemotherapy completion. The primary endpoint was objective response rate (RR) in the brain. Forty-three patients were enrolled. Cerebral, extracerebral, and overall RR by intent to treat analysis were $42 \%$, $35 \%$, and $35 \%$, respectively. Median survival time and time to progression were 7.4 and 4.0 months, respectively. A different phase II study included patients with non-squamous NSCLC and asymptomatic untreated brain metastases who received first-line bevacizumab plus carboplatin and paclitaxel every 3 weeks, or, if already treated earlier, second-line bevacizumab plus erlotinib (Besse et al. 2015). Six-month progression-free survival (PFS) was the primary endpoint. In the first-line cohort $(n=67), 6$-month PFS rate was $56.5 \%$ with a median PFS of 6.7 months and median overall survival of 16.0 months. Investigator-assessed overall RR was $63 \%(61 \%$ in intracranial lesions and $64 \%$ in extracranial lesions).

Monnet et al. reported a phase III trial, which randomized NSCLC patients with asymptomatic brain metastases to receive upfront brain radiotherapy (WBRT or other) and subsequent chemotherapy (platin-pemetrexed and bevacizumab in eligible patients, followed by maintenance pemetrexed with or without bevacizumab) or the same chemotherapy with brain radiotherapy only at cerebral progression (Monnet et al. 2021). The primary endpoint was PFS. Unfortunately, the trial was stopped early because of slow recruitment. Among 95 included patients, 91 were randomized (adenocarcinoma: $92 \%$, extracranial metastases: $58 \%$, without differences between arms.) Significantly, more patients in the radiotherapy arm received radiation compared with those in the chemotherapy alone arm $(87 \%$ versus $20 \% ; p<0.001)$. There were no significant differences for median PFS: 4.7 versus 4.8 months. Median overall survival was 8.5 and 8.3 months, respectively (close to the present study).

Recently, ICI approval has changed the treatment paradigms. Goldberg et al. performed a phase 2 trial of pembrolizumab in patients with NSCLC (or melanoma) with untreated brain metastases $(n=42)$ (Goldberg et al. 2020). Some patients had brain metastases progressing after previous radiotherapy, but none had neurological symptoms or corticosteroid requirement. Patients were separated in two cohorts: cohort 1 had PD-L1 expression of at least $1 \%$ and cohort 2 had PD-L1 less than $1 \%$ or unevaluable. The primary endpoint was the proportion of patients achieving a brain metastasis response. Eleven of 37 patients $(30 \%)$ 
in cohort 1 had a brain metastasis response. There were no responses in cohort 2 . A recent meta-analysis included 12 studies with a total of 566 patients (Teixeira Loiola de Alencar 2021). ICI therapy resulted in an intracranial RR of $16 \%$ and a disease control rate of $45 \%$. There was no difference among patients with brain metastases who were treated with radiation before ICI start and those who were treated with ICI only. However, need for radiotherapy, timing, and sequencing are still under debate in the literature (Li and Yu 2020; Scoccianti et al. 2021). The present study did not include a sufficiently large ICI cohort to contribute to the controversial discussion.

A pooled analysis of three KEYNOTE trials included 171 patients with stable baseline brain metastases (Powell et al. 2021). Their median overall survival was 18.8 months with pembrolizumab plus chemotherapy and 7.6 months with chemotherapy, and median PFS was 6.9 months and 4.1 months, respectively. Objective response rates were higher and duration of response longer with pembrolizumab plus chemotherapy versus chemotherapy. These data led the authors to conclude that combined treatment is a standard-of-care treatment option for treatment-naïve patients with NSCLC and stable brain metastases. As mentioned in the previous paragraph on ICI alone, the present study did not include many patients treated with ICI and chemotherapy. Ideally, larger studies in more homogeneous patient populations, comparable to those for targeted agents (Erickson et al. 2020), will be performed in the future.

Despite its limitations, this study revealed interesting insights. Furthermore, it encourages additional validation of established prognostic models and factors for patients with brain metastases from lung cancer, in the setting of primary systemic therapy. On one hand, the fact that the number of brain metastases and age were not associated with survival in our study might be a result of study size and limited statistical power. On the other hand, eligibility for chemotherapy likely leads to a shift in some baseline characteristics (better organ function, less comorbidity, etc.), potentially resulting in diminished applicability of models that were developed in less-restricted groups of patients, typically patients managed with brain irradiation (Sperduto et al. 2017; Nieder et al. 2018b).

Author contributions $\mathrm{CN}$ participated in the design of the study and performed the statistical analysis. SGA, EH, and CN collected patient data. CN, SGA, and EH conceived of the study and drafted the manuscript. All authors read and approved the final manuscript.

Funding Open Access funding provided by UiT The Arctic University of Norway. None.
Data availability Data will not be shared, but a copy of relevant baseline parameters can be provided to researchers attempting to pool data from several institutions for large-scale analyses.

\section{Declarations}

Conflict of interest SGA has received lecture fees from Bristol Myer Squibb. All other authors declare no conflict of interest.

Ethics approval and consent to participate As a retrospective qualityof-care analysis, no approval from the Regional Committee for Medical and Health Research Ethics (REK Nord) was necessary (national policy in Norway). This research project was carried out according to our institutions' guidelines and with permission to access the patients' data.

Open Access This article is licensed under a Creative Commons Attribution 4.0 International License, which permits use, sharing, adaptation, distribution and reproduction in any medium or format, as long as you give appropriate credit to the original author(s) and the source, provide a link to the Creative Commons licence, and indicate if changes were made. The images or other third party material in this article are included in the article's Creative Commons licence, unless indicated otherwise in a credit line to the material. If material is not included in the article's Creative Commons licence and your intended use is not permitted by statutory regulation or exceeds the permitted use, you will need to obtain permission directly from the copyright holder. To view a copy of this licence, visit http://creativecommons.org/licenses/by/4.0/.

\section{References}

Andratschke N, Kraft J, Nieder C, Tay R, Califano R, Soffietti R, Guckenberger M (2019) Optimal management of brain metastases in oncogenic-driven non-small cell lung cancer (NSCLC). Lung Cancer 129:63-71. https://doi.org/10.1016/j.lungcan.2018.12.009

Barlesi F, Gervais R, Lena H, Hureaux J, Berard H, Paillotin D, Bota S, Monnet I, Chajara A, Robinet G (2011) Pemetrexed and cisplatin as first-line chemotherapy for advanced non-small-cell lung cancer (NSCLC) with asymptomatic inoperable brain metastases: a multicenter phase II trial (GFPC 07-01). Ann Oncol 22:2466-2470. https://doi.org/10.1093/annonc/mdr003

Berghoff AS, Wolpert F, Holland-Letz T, Koller R, Widhalm G, Gatterbauer B, Dieckmann K, Birner P, Bartsch R, Zielinski CC, Weller M, Preusser M (2017) Combining standard clinical blood values for improving survival prediction in patients with newly diagnosed brain metastases-development and validation of the LabBM score. Neuro Oncol 19:1255-1262. https://doi.org/10. 1093/neuonc/now290

Bernardo G, Cuzzoni Q, Strada MR, Bernardo A, Brunetti G, Jedrychowska I, Pozzi U, Palumbo R (2002) First-line chemotherapy with vinorelbine, gemcitabine, and carboplatin in the treatment of brain metastases from non-small-cell lung cancer: a phase II study. Cancer Invest 20:293-302. https://doi.org/10.1081/cnv120001173

Besse B, Le Moulec S, Mazières J, Senellart H, Barlesi F, Chouaid C, Dansin E, Bérard H, Falchero L, Gervais R, Robinet G, Ruppert AM, Schott R, Léna H, Clément-Duchêne C, Quantin X, Souquet PJ, Trédaniel J, Moro-Sibilot D, Pérol M, Madroszyk AC, Soria JC (2015) Bevacizumab in patients with nonsquamous non-small cell lung cancer and asymptomatic, untreated brain metastases (BRAIN): a nonrandomized, phase II study. Clin Cancer Res 21:1896-1903. https://doi.org/10.1158/1078-0432.CCR-14-2082 
Chen G, Huynh M, Chen A, Fehrenbacher L, Gandara D, Lau D (2008) Chemotherapy for brain metastases in small-cell lung cancer. Clin Lung Cancer 9:35-38. https://doi.org/10.3816/CLC.2008.n.006

de Teixeira Loiola Alencar V, Guedes Camandaroba MP, Pirolli R, Fogassa CAZ, Cordeiro de Lima VC (2021) Immunotherapy as single treatment for patients with NSCLC with brain metastases: a systematic review and meta-analysis-the META-L-BRAIN study. J Thorac Oncol 16:1379-1391. https://doi.org/10.1016/j. jtho.2021.04.014

Du TQ, Li X, Zhong WS, Tian JD, Zhao YX, Liu D (2021) Brain metastases of lung cancer: comparison of survival outcomes among whole brain radiotherapy, whole brain radiotherapy with consecutive boost, and simultaneous integrated boost. J Cancer Res Clin Oncol 147:569-577. https://doi.org/10.1007/ s00432-020-03359-8

Erickson AW, Brastianos PK, Das S (2020) Assessment of effectiveness and safety of osimertinib for patients with intracranial metastatic disease: a systematic review and meta-analysis. JAMA Netw Open 3:e201617. https://doi.org/10.1001/jamanetworkopen.2020.1617

Fuchs J, Früh M, Papachristofilou A, Bubendorf L, Häuptle P, Jost L, Zippelius A, Rothschild SI (2021) Resection of isolated brain metastases in non-small cell lung cancer (NSCLC) patientsevaluation of outcome and prognostic factors: a retrospective multicenter study. PLoS One 16:e0253601. https://doi.org/10. 1371/journal.pone.0253601

Goldberg SB, Schalper KA, Gettinger SN, Mahajan A, Herbst RS, Chiang AC, Lilenbaum R, Wilson FH, Omay SB, Yu JB, Jilaveanu L, Tran T, Pavlik K, Rowen E, Gerrish H, Komlo A, Gupta R, Wyatt H, Ribeiro M, Kluger Y, Zhou G, Wei W, Chiang VL, Kluger HM (2020) Pembrolizumab for management of patients with NSCLC and brain metastases: long-term results and biomarker analysis from a non-randomised, open-label, phase 2 trial. Lancet Oncol 21:655-663. https://doi.org/10.1016/S1470-2045(20)30111-X

Kepka L, Socha J, Sas-Korczynska B (2021) Radiotherapy for brain metastases from small-cell lung cancer in distinct clinical indications and scenarios. J Thorac Dis 13:3269-3278. https://doi.org/ 10.21037/jtd.2019.10.51

Lee DH, Han JY, Kim HT, Yoon SJ, Pyo HR, Cho KH, Shin SH, Yoo H, Lee SH, Lee JS (2008) Primary chemotherapy for newly diagnosed nonsmall cell lung cancer patients with synchronous brain metastases compared with whole-brain radiotherapy administered first: result of a randomized pilot study. Cancer 113:143-149. https://doi.org/10.1002/cncr.23526

Li W, Yu H (2020) Separating or combining immune checkpoint inhibitors (ICIs) and radiotherapy in the treatment of NSCLC brain metastases. J Cancer Res Clin Oncol 146:137-152. https://doi. org/10.1007/s00432-019-03094-9

Minotti V, Crinò L, Meacci ML, Corgna E, Darwish S, Palladino MA, Betti M, Tonato M (1998) Chemotherapy with cisplatin and teniposide for cerebral metastases in non-small cell lung cancer. Lung Cancer 20:93-98

Monnet I, Vergnenègre A, Robinet G, Berard H, Lamy R, Falchero L, Vieillot S, Schott R, Ricordel C, Chouabe S, Thomas P, Gervais R, Madroszyk A, Abdiche S, Chiappa AM, Greillier L, Decroisette C, Auliac JB, Chouaiid C, GFPC 02-13 (METAL2) investigators (2021) Phase III randomized study of carboplatin pemetrexed with or without bevacizumab with initial versus "at progression" cerebral radiotherapy in advanced non squamous non-small cell lung cancer with asymptomatic brain metastasis. Ther Adv Med Oncol 13:17588359211006984. https://doi.org/10.1177/17588 359211006983

Nieder C, Hintz M, Oehlke O, Bilger A, Grosu AL (2017) Validation of the graded prognostic assessment for lung cancer with brain metastases using molecular markers (lung-molGPA). Radiat Oncol 12:107. https://doi.org/10.1186/s13014-017-0844-6
Nieder C, Yobuta R, Mannsåker B (2018a) Second re-irradiation of brain metastases: a review of studies involving stereotactic radiosurgery. Cureus 10:e3712. https://doi.org/10.7759/cureus.3712

Nieder C, Mehta MP, Geinitz H, Grosu AL (2018b) Prognostic and predictive factors in patients with brain metastases from solid tumors: A review of published nomograms. Crit Rev Oncol Hematol 126:13-18. https://doi.org/10.1016/j.critrevonc.2018.03.018

Nieder C, Guckenberger M, Gaspar LE, Rusthoven CG, De Ruysscher D, Sahgal A, Nguyen T, Grosu AL, Mehta MP (2019a) Management of patients with brain metastases from non-small cell lung cancer and adverse prognostic features: multi-national radiation treatment recommendations are heterogeneous. Radiat Oncol 14:33. https://doi.org/10.1186/s13014-019-1237-9

Nieder C, Haukland E, Mannsåker B, Pawinski AR, Yobuta R, Dalhaug A (2019b) Presence of brain metastases at initial diagnosis of cancer: patient characteristics and outcome. Cureus 11:e4113. https://doi.org/10.7759/cureus.4113

Nieder C, Dalhaug A, Pawinski A (2019c) External validation of the LabBM score in patients with brain metastases. J Clin Med Res 11:321-325. https://doi.org/10.14740/jocmr3746

Nieder C, Reigstad A, Carlsen EA, Flatøy L, Tollåli T (2020) Initial experience after transition to immune checkpoint inhibitors in patients with non-small cell lung cancer treated in a rural healthcare region. Cureus 12(2):e7030. https://doi.org/10.7759/cureus. 7030

Nieder C, Mehta MP, Guckenberger M, Gaspar LE, Rusthoven CG, Sahgal A, Grosu AL, De Ruysscher D (2021a) Assessment of extracranial metastatic disease in patients with brain metastases: how much effort is needed in the context of evolving survival prediction models? Radiother Oncol 159:17-20. https://doi.org/ 10.1016/j.radonc.2021.02.038

Nieder C, Dalhaug A, Haukland E (2021b) Recursive partitioning analysis of systemic therapy after radiotherapy in patients with brain metastases. Oncol Res Treat 44:86-92. https://doi.org/10. $1159 / 000513975$

Powell SF, Rodríguez-Abreu D, Langer CJ, Tafreshi A, Paz-Ares L, Kopp HG, Rodríguez-Cid J, Kowalski DM, Cheng Y, Kurata T, Awad MM, Lin J, Zhao B, Pietanza MC, Piperdi B, Garassino MC (2021) Outcomes with pembrolizumab plus platinum-based chemotherapy for patients with non-small-cell lung cancer and stable brain metastases: pooled analysis of KEYNOTE-021, 189, and 407. J Thorac Oncol 16:1883-1892. https://doi.org/10.1016/j. jtho.2021.06.020

Sacks P, Rahman M (2020) Epidemiology of brain metastases. Neurosurg Clin N Am 31:481-488. https://doi.org/10.1016/j.nec.2020. 06.001

Scoccianti S, Olmetto E, Pinzi V, Osti MF, Di Franco R, Caini S, Anselmo P, Matteucci P, Franceschini D, Mantovani C, Beltramo G, Pasqualetti F, Bruni A, Tini P, Giudice E, Ciammella P, Merlotti A, Pedretti S, Trignani M, Krengli M, Giaj-Levra N, Desideri I, Pecchioli G, Muto P, Maranzano E, Fariselli L, Navarria P, Ricardi U, Scotti V, Livi L (2021) Immunotherapy in association with stereotactic radiotherapy for Non-Small Cell Lung Cancer brain metastases: results from a multicentric retrospective study on behalf of AIRO. Neuro Oncol 23:1750-1764. https://doi.org/ 10.1093/neuonc/noab129

Sperduto PW, Yang TJ, Beal K, Pan H, Brown PD, Bangdiwala A, Shanley R, Yeh N, Gaspar LE, Braunstein S, Sneed P, Boyle J, Kirkpatrick JP, Mak KS, Shih HA, Engelman A, Roberge D, Arvold ND, Alexander B, Awad MM, Contessa J, Chiang V, Hardie J, Ma D, Lou E, Sperduto W, Mehta MP (2017) Estimating survival in patients with lung cancer and brain metastases: an update of the graded prognostic assessment for lung cancer using molecular markers (Lung-molGPA). JAMA Oncol 3:827-831. https://doi.org/10.1001/jamaoncol.2016.3834 
Wang L, Sheng Z, Zhang J, Song J, Teng L, Liu L, Li Q, Wang B, Li B (2021) Comparison of lorlatinib, alectinib and brigatinib in ALK inhibitor-naive/untreated ALK-positive advanced non-small-cell lung cancer: a systematic review and network meta-analysis. J Chemother. https://doi.org/10.1080/1120009X.2021.1937782
Publisher's Note Springer Nature remains neutral with regard to jurisdictional claims in published maps and institutional affiliations. 